\title{
Ordem Visiocêntrica do Discurso: uma proposta de reflexão teórica sobre os letramentos de pessoas com deficiência visual
}

\author{
Visio-centric order of discourse: a proposal of theoretical \\ reflection about the literacies of a people with visual \\ impairment \\ Beatriz Furtado Alencar Lima' \\ Professora assistente do Departamento de Letras Estrangeiras da \\ Universidade Federal do Ceará (UFC) - Fortaleza - Ceará, Brasil \\ Izabel Magalhães (UFC) ${ }^{2}$ \\ Professora visitante na Universidade Federal do Ceará (UFC) - Fortaleza - Ceará, Brasil
}

\section{ABSTRACT}

In this paper, we present theoretical insights about the literacies of people with visual impairment from the perspective of what we have named a vision-centric order of discourse. We examine this order and its implication for the discourse representations of a woman with visual impairment about her literacy practices. The theoretical and methodological background for our analysis of such representations is Critical Discourse Analysis (CDA)

1. Doutora pelo Programa de Pós-Graduação em Linguística da UFC na linha de pesquisa: Práticas Discursivas. Tem atuado nas seguintes áreas de investigação: estudos críticos do letramento e do discurso; letramentos de pessoas com deficiência visual; e ensino de línguas estrangeiras para pessoas com deficiência. Mestra em Linguística Aplicada pelo Programa de Pós-Graduação em Linguística Aplicada da Universidade Estadual do Ceará (UECE) - Ceará, Brasil.

2. Pesquisadora colaboradora na Universidade de Brasília (UnB) - Brasília, Brasil. Seu livro mais recente é Discursos e práticas de letramento: formação de professores e pesquisa etnográfica (2012). 
and its transdisciplinary relations with Systemic Functional Linguistics. The study focused on the analysis of Representational Meaning (Fairclough 2003), based on the concept of an ideational metafunction, which is manifested within the clause structure through the transitivity system (Halliday \& Matthiessen 2004). The results indicate that the discursive point of view of the participant of the present study oscillates between an explicit claim for a vision-centric order of discourse and a conformative adjustment to such discourse order. By bringing these two distinct points of view of the participant, we aim to contribute to a more efficient use of language by visually impaired people, thus leading to a more effective destabilization in a society that still lacks appropriate accessibility practices.

Keywords: discursive representations; positions; reading and writing; people with visual impairments.

\section{RESUMO}

Apresenta-se uma reflexão teórica sobre os letramentos de pessoas com deficiência visual a partir da Ordem Visiocêntrica do Discurso. Discute-se essa ordem e sua implicação nas representações discursivas de uma pessoa com deficiência visual nas práticas de letramento em que se encontra situada. Para isso, adota-se o aporte teórico-metodológico da Análise de Discurso Crítica com a Linguística Sistêmico-Funcional. Detendo-se no estudo do Significado Representacional (Fairclough 2003), analisar-se-á a metafunção ideacional. As análises sugerem que a posição discursiva da participante pesquisada oscila entre uma reivindicação explícita a uma Ordem Visiocêntrica do Discurso e um ajustamento conformativo a ela. Com este estudo, almeja-se apresentar subsidios para que o discurso reivindicativo de uma pessoa com deficiência visual possa gerar desestabilizações em uma sociedade inacessivivel.

Palavras-chave: representações discursivas; posições; leitura e escrita; pessoas com deficiência visual.

\section{Introdução}

O trabalho que ora apresentamos ocupa-se em discorrer sobre uma das facetas que constitui a diversificada realidade dos letramentos de pessoas com deficiência visual no contexto brasileiro. Nesse cenário, 
nos últimos 20 anos, observamos o advento de uma forma intensa de políticas e legislações que visam estabelecer e assegurar o direito pleno à acessibilidade para as pessoas com deficiência visual. É fato inegável a importância desses marcos regulatórios para o processo de estabelecimento de práticas atitudinais que buscam a desestabilização de ordens hegemônicas, mantenedoras de complexas assimetrias, desigualdades e injustiças no contexto de vida de pessoas com deficiência. A pesquisa que ora desenvolvemos constata, no entanto, um grande descompasso entre o que estabelecem esses marcos regulatórios e a realidade dos múltiplos letramentos das pessoas cegas.

A fim de refletirmos, de maneira mais aprofundada, sobre o que se encontra submerso a essa situação de descompasso, propomos uma discussão teórica a respeito do que denominamos como Ordem Visiocêntrica do Discurso. Para chegarmos a uma definição sobre o que vem a ser essa ordem e sobre suas implicações para os letramentos de pessoas com deficiência visual, baseamo-nos em Fairclough (2003); de maneira mais específica, nosso olhar volta-se para uma leitura interpretativa mais acurada a respeito da articulação entre dois dos elementos (ou momentos) da prática social - 1) Ação e Interação (Relação Corpóreo-Ambiental ${ }^{3}$ ) e 2) Discurso - nas práticas sociais de leitura e de escrita em que estão situadas as pessoas com deficiência visual.

Com o intuito de proporcionar uma compreensão mais clara e elucidativa sobre o que entendemos por uma Ordem Visiocêntrica do Discurso, na seção analítica deste artigo, detemo-nos nas posições de uma pessoa com deficiência visual no tocante ao contexto em que se encontra situada, para a realização de atividades que envolvem o uso da leitura e da escrita.

3. Na próxima seção, explicaremos a definição de Relação Corpóreo-Ambiental para nos referirmos ao primeiro elemento que Fairclough (2003) elenca como um dos momentos da prática social, qual seja, o de Ação e Interação. Na seção adiante, explicaremos o que vem a ser essa relação. 


\section{Análise de discurso crítica, ideologia e modelo social de deficiência: fundamentos para uma reflexão sobre a Ordem Visiocêntrica do Discurso}

Para a análise das posições da pessoa com deficiência visual que discutiremos neste artigo, pressupomos que uma grande extensão da paisagem linguística ${ }^{4}$ em que se encontram as pessoas cegas está conformada por uma ordem a que denominamos de Ordem Visiocêntrica do Discurso. Para uma reflexão sobre essa ordem, fundamentamo-nos no diálogo entre a Análise do Discurso Crítica (doravante ADC) e a concepção de ideologia de Thompson (2011). A ADC como "[...] o estudo das relações dialéticas entre o discurso (inclusive a linguagem, mas também outras formas de semiose, por exemplo, a linguagem do corpo ou imagens visuais) e outros elementos das práticas sociais" (Fairclough 2012:94-95); e a concepção de ideologia de Thompson (2011:91), segundo a qual a ideologia “[...] é, por natureza, hegemônica, no sentido de que ela, necessariamente, serve para estabelecer e sustentar relações de dominação e, com isso, serve para reproduzir a ordem social que favorece indivíduos e grupos dominantes".

Subsidia igualmente nossa compreensão sobre a Ordem Visiocêntrica do Discurso "[...] a revolução dos estudos sobre deficiência surgidos no Reino Unido e nos Estados Unidos nos anos 1970" (Diniz 2012:9), conhecido como Modelo Social de Deficiência. Esse modelo tem como momento precursor "[...] a primeira insurgência ativa das pessoas com deficiência com um impacto assinalável [...]" (Martins 2006:110), o Center for Independent Living, primeiro centro de vida independente, criado por pessoas com deficiência e para elas, no contexto universitário estadunidense.

O referido movimento centrou-se na defesa dos direitos das pessoas com deficiência e teve repercussões em vários contextos, como no britânico. Nesse cenário, surge em 1974 uma organização que agrega várias organizações de pessoas com deficiência, a Union of the Physically Impaired Against Segregation (Upias). Essa organização traz para

4. Trata-se de termo utilizado por Coulmas (2014). Discorreremos sobre a definição de paisagem linguística, bem como sobre suas implicações para nosso trabalho, no momento analítico deste artigo (seção 4). 
a ordem do dia a necessidade de uma profunda transformação sobre as concepções dominantes que envolvem as pessoas com deficiência por meio de uma (re)construção de valores que passa a entender a deficiência da seguinte forma:

[...] um conceito complexo que reconhece o corpo com lesão, mas que também denuncia a estrutura social que oprime a pessoa deficiente. Assim como outras formas de opressão pelo corpo, como o sexismo ou o racismo, os estudos sobre deficiência descortinaram uma das ideologias mais opressoras de nossa vida social: a que humilha e segrega o corpo deficiente. (Diniz 2012:10).

Em nota de rodapé sobre o corpo deficiente, Diniz (2012:10) apresenta-nos a explicação que se segue, de suma importância para o que concebemos como Ordem Visiocêntrica do Discurso:

'Ideologia de opressão aos deficientes' é uma tradução composta para o neologismo disablism em língua inglesa. O conceito de disablism é uma analogia ao sexismo e ao racismo. A ideologia que oprime os deficientes supõe que há uma superioridade dos corpos não deficientes em comparação com os corpos deficientes.

A partir do diálogo transdisciplinar que se estabelece entre as ontologias aqui apresentadas, objetivamos tornar explícita uma ordem implicada nas representações de Leda sobre alguns de seus contextos de uso da leitura e da escrita. Além dessa explicitação, mostramos a posição da participante a respeito do que concebemos por uma Ordem Visiocêntrica do Discurso. Para a consecução desse objetivo, adotamos (conforme veremos na seção 3) igualmente a complementação que se constrói entre a ADC e a Linguística Sistêmico-Funcional (doravante LSF), uma vez que essas duas disciplinas juntas:

[...] completam um arsenal teórico e metodológico que dá conta da natureza da linguagem como fenômeno integral e social. A ADC defende a ideia de que os sistemas linguísticos são abertos à vida social. Assim, a linguagem, entendida como prática social, interage, dialeticamente, com os vários domínios que configuram o mundo social. (Silva 2013:54).

Entendendo o discurso como um dos elementos das práticas sociais, "[...] podemos dizer que ele figura de três principais maneiras na prática 
social. O discurso figura como: gêneros (maneiras de agir), discursos (maneiras de representar), estilos (maneiras de ser)" (Fairclough 2003:26). Dentro da complementação entre ADC e LSF, analisamos o tipo de significado do texto que Fairclough (2003) classifica como representação, ou seja, o Significado Representacional, o qual corresponde à função ideacional de Halliday e Matthiessen (2004).

Embora já bastante citado e enfatizado em trabalhos anteriores (Fairclough 2003, 2012; Ramalho \& Resende 2009, 2011), reiteramos que a divisão entre os significados representacional, identificacional e acional e as metafunções ideacional, interpessoal e textual (com ênfase neste artigo para o aspecto representacional do texto e para a sua função ideacional) dá-se com o fim de melhor operacionalizar as análises de nossos materiais linguísticos. Isso significa dizer que esses significados e funções atuam de maneira complementar e simultânea no processo de texturização.

\section{Sobre a Ordem Visiocêntrica do Discurso}

Fairclough (2012), ao discorrer sobre a ordem do discurso, diz que um dos aspectos implicados na distribuição de tal ordem é a dominância. Consoante o autor:

[...] algumas formas de fazer sentido são dominantes ou regulares em uma ordem particular do discurso, outras são marginais, ou opositivas, ou 'alternativas’. [...] Uma ordem do discurso não é um sistema fechado ou rígido, mas, ao contrário, é um sistema aberto, que é posto em risco pelo que acontece nas interações reais. (Fairclough 2012:96-97).

Essa perspectiva da relativa dominância de alguns sentidos que encontramos na ordem do discurso, em consonância com: 1) a reorientação que Thompson propõe para o estudo da ideologia ${ }^{5}$; e 2) a introdução da ideologia da opressão pela deficiência proposta pelo

5. “[...] podemos reorientar o estudo da ideologia para as múltiplas e diferentes maneiras como as formas simbólicas foram usadas, e continuam a ser, a serviço do poder, dentro das sociedades ocidentais modernas ou dos contextos sociais situados em diferentes pontos no tempo ou espaço" (Thompson 2011:116). 
Modelo Social de Deficiência ${ }^{6}$, auxilia-nos na tarefa de trazer à tona e desnaturalizar algumas formas de fazer sentido - ainda dominantes em nossa sociedade - utilizadas a serviço do poder. Para o contexto deste trabalho, denominamos a essas formas de centralidades como Corpóreo-Discursivas Dominantes.

Uma das respostas sociais construídas, desde o advento da modernidade, para a vida de homens e mulheres considerados como deficientes vêm a ser essas centralidades Corpóreo-Discursivas Dominantes, que estabelecem o que é a normalidade nas atividades humanas ligadas a aspectos sensoriais, motores e cognitivos. Com o estabelecimento dessa centralidade, o que não se ajusta a ela encontra-se, consequentemente, à margem das maneiras concebidas como normais, corretas, desejáveis e até mesmo legais, em vários conjuntos de práticas da experiência humana.

Conforme Fairclough (2003:25, tradução nossa), o discurso relaciona-se dialeticamente com outros momentos da prática social:

As práticas sociais podem ser vistas como articulações de diferentes tipos de elementos sociais, os quais estão associados com áreas particulares da vida social - a prática social do ensino em sala de aula na educação britânica contemporânea, por exemplo. O ponto importante sobre as práticas sociais, desde a perspectiva deste livro, é que elas articulam o discurso (portanto, a linguagem), juntamente com outros elementos sociais não discursivos. Podemos ver qualquer prática social como uma articulação destes elementos: ação e interação; relações sociais; pessoas (com crenças, atitudes, histórias, etc.); mundo material; discurso. Então, por exemplo, o ensino em sala de aula articula-se com maneiras particulares de uso da linguagem (por parte de ambos, professores e alunos) com as relações sociais da sala de aula, a estrutura e o uso das sala como um espaço físico, e por aí em diante.

Com base nessa discussão, propomos um aprofundamento sobre a dialética entre dois desses momentos da prática social que Fairclough apresenta, quais sejam: o momento do Discurso e o momento da Ação e Interação, ao qual denominaremos como Relação CorpóreoAmbiental.

6. Com a introdução da ideologia da opressão pela deficiência, "[...] a deficiência passou a ser compreendida como uma experiência de opressão compartilhada por pessoas com diferentes tipos de lesões" (Diniz 2012:23). 
Se, “[...] no momento semiótico da prática (discurso), temos a articulação de outros três elementos ${ }^{7}$, que configuram, juntos, o momento discursivo da prática" (Ramalho \& Resende 2011:42), no momento semiótico da Relação Corpóreo-Ambiental (Ação e Interação), temos a articulação de modos, atividades corporais e $\operatorname{meios}^{8}$, os quais configuram o momento da relação corpo humano e meio ambiente da prática social. Ao ordenamento existente entre os elementos que fazem parte dessa articulação chamaremos de Ordem Corpóreo-Material.

Entendemos, pois, essa Ordem Corpóreo-Material como um ordenamento de/entre modos, meios e atividades (sensoriais, cognitivas e físicas) que implica como a experiência corporal humana vivencia a sua ação e interação com o meio ambiente em que está situada. Desde uma perspectiva de normalidade dos corpos, encontramos a construção de ordenamentos das experiências corporais humanas centradas em dominâncias que ditam os modos, os meios e as atividades que são eleitas como hegemônicas - leia-se como normais - nas interações das pessoas com o meio ambiente no qual estão situadas.

As organizações da ordem do discurso, em articulação com as da Ordem Corpóreo-Material, conformam as centralidades CorpóreoDiscursivas Dominantes a que nos referimos. Uma das manifestações dessas centralidades são as ordens discursivas e corporais dominantes, que podemos classificar como visiocêntricas, audiocêntricas, erotocêntricas, etc. Dessa maneira, podemos dizer que a Ordem Visiocêntrica do Discurso - conceito que desenvolvemos nesta pesquisa - constrói-se e organiza-se pelas articulações entre maneiras de representar, ser e agir por meio do discurso e pelas maneiras de modular, mediar e experienciar a relação corpóreo-ambiental dos/as atores/as sociais em suas práticas. Ou seja, são as articulações entre o momento do discurso e a

7. Os três elementos a que se referem as autoras são os elementos conformadores de uma ordem do discurso, quais sejam: Gêneros, Discursos e Estilos. "Podemos dizer que o discurso figura de três principais maneiras nas práticas sociais. Ele figura como: Gêneros (maneiras de agir); Discursos (maneiras de representar); Estilos (maneiras de ser)" (Fairclough 2003:26, tradução nossa).

8. Entendemos o modo como a imagem, a escrita, os gestos, imagens em movimento etc., ao passo que o meio configura-se como o suporte pelo qual os modos materializamse; por exemplo, o papel, a tela do computador e o nosso próprio corpo constituem-se como meios utilizados para que possamos agir e interagir com/na linguagem (atividades corporais) em nossas práticas sociais. 
Relação Corpóreo-Ambiental que definirão o que concebemos como a Ordem Visiocêntrica do Discurso.

À materialização nas linguagens discursiva e corporal dessas centralidades dominantes, conforme já apontamos, denominaremos de Ordens Discursivas e Corporais Hegemônicas, as quais podem ser classificadas/divididas em Ordem Visiocêntrica do Discurso, Ordem Audiocêntrica do Discurso, Ordem Erotocêntrica do Discurso, Ordem Grafocêntrica (centrada na escrita alfabética padrão), entre outras. Essas ordens tanto estruturam como são estruturadas por discursos e práticas em torno de atividades da vida social humana, tendo como foco um padrão de normalidade estabelecido como central para a interação com o meio ambiente. Mais especificamente, no que concerne à atividade social de interação com a leitura e com a escrita, essas ordens estruturam e organizam paradigmas centrados em discursos e atividades corporais nos quais predominam determinados padrões de percepção, ação e interação com o meio ambiente detentores de uma posição hegemônica e opressiva na organização de práticas de letramento.

Com base nesse posicionamento e na perspectiva de Fairclough (2003) sobre a inter-relação entre as performances linguísticas e corporais nos eventos sociais ${ }^{9}$, propomos uma perspectiva sobre o letramento como uma atividade de interação com textos (estejam eles ou não no modo escrito), na qual pessoas, com suas crenças, atitudes, histórias, etc., situadas em um mundo material, agem e interagem em suas relações sociais por meio do Discurso. Considerando o letramento como uma prática social, centrar-nos-emos, para os propósitos do presente trabalho, na dialética que se estabelece entre o elemento da Ação e Interação ${ }^{10}$ (Ordem Corpóreo-Material) e o elemento do

9. "Uma maneira pela qual as pessoas podem agir e interagir no curso dos eventos sociais é falando ou escrevendo. Esta não é a única maneira. Muitos eventos sociais apresentam um caráter textual elevado, outros não. Por exemplo, enquanto a fala está presente de certa maneira em um jogo de futebol (i.e. o jogador pedindo a bola), ela é um elemento relativamente marginal, e muitas das ações no jogo são não linguísticas. Ao contrário, muito da ação envolvida em uma palestra é linguística - o que o conferencista diz, o que está escrito nos cabeçalhos e folhetos, as notas tomadas pelas pessoas que ouvem a palestra. Mas até mesmo uma palestra não é somente linguagem - ela é uma performance corporal, bem como uma performance linguística, e é provável que envolva ações físicas, como o conferencista operando um retroprojetor" (Fairclough 2003:21-22, tradução nossa).

10. Que aqui denominamos, conforme exposto, como Relação Corpóreo-Ambiental. 
Discurso (Ordem do Discurso). Isso não significa dizer que os demais momentos da prática social não estejam presentes. Futuros trabalhos poderão explorar a dialética entre os demais elementos. Para este estudo, entretanto, nosso foco captura a dialética entre o Discurso e as Relações Corpóreo-Ambientais.

Na próxima seção, apresentaremos uma análise do significado representacional de Fairclough para esclarecer o funcionamento da Ordem Visiocêntrica do Discurso.

\section{Metodologia}

Com o intuito de proporcionar uma compreensão mais clara e elucidativa sobre o que entendemos por uma Ordem Visiocêntrica do Discurso, na seção analítica deste artigo, detemo-nos nas posições de uma pessoa com deficiência visual no tocante ao contexto em que se encontra situada, para a realização de atividades que envolvem o uso da leitura e da escrita. Para isso, nesta seção, explicitaremos a metodologia de pesquisa adotada, bem como a metodologia que empregamos para a análise dos dados gerados.

Neste artigo, o que apresentamos sobre as posições de uma pessoa com deficiência visual a respeito das práticas de letramento em que está situada foi retirado do corpus $^{11}$ de uma pesquisa de doutorado sobre os múltiplos letramentos de pessoas com deficiência visual. Construímos nosso corpus por meio de uma pesquisa discursiva que se utilizou dos seguintes instrumentos metodológicos da etnografia: observações participantes, elaboração de diários de campo, entrevistas semiestruturadas e diários de participantes baseados em entrevistas semiestruturadas. A pesquisa, de orientação qualitativa, contou com a participação de 10 pessoas com deficiência visual (seis mulheres e quatro homens).

11. Os trechos das entrevistas que aparecerão nas análises deste artigo fazem parte do projeto de doutoramento de Beatriz Furtado Alencar Lima, sob a orientação de Izabel Magalhães. O projeto vincula-se ao Programa de Pós-Graduação em Linguística da UFC e foi devidamente aprovado pelo Comitê de Ética em Pesquisa da UFC: ofício número 185/11, protocolo COMEPE, número 134/11. 
Nosso trabalho de coleta e geração de dados aconteceu em cinco diferentes instituições ${ }^{12}$, nas quais esses/as participantes estavam situados/as em atividades laborais e/ou acadêmicas que requeriam o uso da leitura e da escrita. $\mathrm{O}$ trabalho de campo teve a duração de quase dois anos e, ao final desse momento, construímos um corpus composto por 42 diários de campo, 22 transcrições de entrevistas semiestruturadas e 31 diários de participantes. Para os fins deste artigo, valer-nos-emos dos diários de campo e de trechos das transcrições de duas entrevistas que fizemos com a participante Leda ${ }^{13}$.

Leda, à época de nossa primeira entrevista, tinha 45 anos, conforme ela mesma descreve, "de gente e de cega". Ela nasceu com baixa visão devido à retinose pigmentar; com o passar dos anos, foi perdendo o resíduo de visão que tinha. Possui nível superior e é pedagoga com especialização em Metodologia do Ensino Fundamental e Médio. Atua como professora do Estado do Ceará e da Prefeitura de Fortaleza há 15 anos, trabalhando no Centro Educacional de Referência pelo Estado e em uma Associação de Cegos pela Prefeitura. No Centro de Referência, atua no apoio pedagógico, atendendo a crianças, adolescentes e adultos cegos e com deficiência associada ${ }^{14}$; na Associação, trabalha com a Educação de Jovens e Adultos (EJA).

Em nossas análises, fecharemos nosso foco, portanto, nas representações discursivas da participante Leda sobre contextos que envolvem a utilização do letramento. Para isso, analisaremos textos de duas entrevistas realizadas que fizemos com ela, no contexto de uma pesquisa discursiva crítica de caráter etnográfico, seguindo os preceitos teórico-metodológicos preconizados por Magalhães (2000), Resende (2009) e Rios (2009).

No tocante à metodologia de análise dos dados, trabalharemos com o Significado Representacional (Fairclough 2003) a partir das categorias

12. Tratava-se de instituições públicas (federais, estaduais e municipais) localizadas no município de Fortaleza, quais sejam: um Centro de Apoio à Pessoa com Deficiência Visual, uma Secretaria de Acessibilidade, duas instituições de Ensino Superior, uma Associação de Cegos, um Espaço Cultural do Estado do Ceará e uma Biblioteca Pública.

13. Para preservar a identidade da participante que aceitou contribuir com o trabalho, usamos um nome fictício.

14. Trata-se da presença de mais uma deficiência associada em uma mesma pessoa. Por exemplo, pessoas com surdo-cegueira ou cegueira e transtorno do espectro autista. 


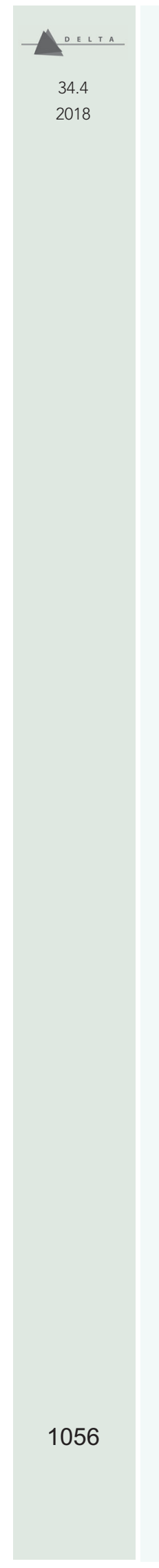

Beatriz Furtado Alencar Lima, Izabel Magalhães

léxico-gramaticais que Halliday e Matthiessen (2004) sistematizam para a compreensão da oração pelo sistema de transitividade (Metafunção Ideacional). Embora nos detenhamos na oração como representação, a oração como troca (Metafunção Interpessoal) e a oração como mensagem (Metafunção Textual) serão abordadas, em alguns momentos, para melhor fundamentar nossas leituras interpretativas.

\section{Análises}

Ao analisarmos as representações (Significado Representacional) que Leda constrói a respeito de alguns de seus contextos de letramento, trazemos à tona também os posicionamentos dessa participante sobre a Ordem Visiocêntrica do Discurso em que se encontra situada. Para a análise dessas representações, as quais trazem consigo as posições implícitas de Leda a respeito da ordem a que nos referimos, valemonos da Metafunção Ideacional (Halliday \& Matthiessen 2004), que se realiza na oração através do sistema de transitividade. "Fairclough relaciona o significado representacional ao conceito de discurso como modos de representação de aspectos do mundo, os quais podem ser representados diferentemente, de acordo com a perspectiva de mundo adotada" (Silva 2008:27).

Embora incorporando todos os elementos do sistema de transitividade, constituído pelos elementos experienciais básicos e processos, participantes e circunstâncias, nossas análises centram-se nos processos, tendo em vista a figura que Halliday e Matthiessen (2004) apresentam sobre os elementos centrais e periféricos na estrutura experiencial da oração. Nesta, o processo é apresentado como elemento central. "Não há, portanto, um evento se não houver um processo expresso por um grupo verbal. A ocorrência de participantes é inerente ao processo, ao passo que as circunstâncias são um elemento opcional" (Taveira 2009:74). Essa centralidade que tem o processo no sistema de transitividade pode ser mais bem compreendida com o que Halliday e Matthiessen (2004:170, tradução nossa) esclarecem-nos sobre os tipos de processo no estudo da oração como representação:

Nossa impressão mais forte da experiência é que ela consiste de um fluxo de eventos ou 'atividades'. Esse fluxo de eventos está fragmentado em 
frações de mudança pela gramática da oração: cada fração de mudança está modelada como uma figura - o acontecer, o fazer, o sentir, o dizer, o ser, o ter (ver Halliday \& Matthiessen 1999). Todas as figuras consistem de um processo que se desenvolve no tempo e de participantes diretamente envolvidos nesse processo, de alguma maneira; e, além disso, pode haver circunstâncias de tempo, espaço, causa, modo ou de alguns outros tipos. Essas circunstâncias não estão diretamente envolvidas no processo; em vez disso, elas são subordinadas ao processo.

Partindo desses pressupostos teóricos que a Gramática SistêmicoFuncional oferece-nos, iniciamos nossas reflexões interpretativas. Nas análises que se seguem, encontramos a questão da dificuldade e da falta de materiais acessíveis, bem como a dificuldade do acesso à educação. São questões recorrentes entre as reivindicações nas falas das pessoas cegas que pesquisamos. Começamos, então, com uma fala de Leda na qual figura seu desabafo sobre a dificuldade que é, em sua vida, ter acesso a tecnologias que levem em conta a sua diversidade funcional.

Excerto (1): Aí quer dizer (1) ${ }^{15}$ a gente vive em desvantagem em relação às outras pessoas nessas questões, e isso não significa dizer que (2) nós, pessoas cegas, estamos acostumadas a conviver com essas dificuldades, que não possamos encontrar a nossa maneira, o nosso meio de conviver com isso daí, só que (3) as adaptações quem faz sou eu, elas não vieram adaptadas para eu usar, elas não vieram para mim, eu estou usando pela minha necessidade, então, (4) como eu tenho necessidade, (5) eu encontro o meu meio, a minha forma, o meu jeito de poder utilizar aquela ferramenta, aquela tecnologia, para eu poder ter acesso, ou pelo menos conviver como todo mundo. (Leda, grifos nossos) ${ }^{16}$.

Leda inicia seu relato reivindicativo por meio de uma constatação categórica relativa ao contexto linguístico excludente em que ela e as demais pessoas cegas encontram-se situadas: "[...] a gente vive em desvantagem em relação às outras pessoas [...]". A análise semântica dessa passagem mediante o Sistema de Transitividade apresenta a constituição que se segue:

15. A numeração que utilizamos nos excertos ( 1 e 3 ) tem o objetivo de orientar o/a leitor/a durante o acompanhamento das análises.

16. Entrevista realizada em Fortaleza, Ceará, no dia 7 de novembro de 2011. 


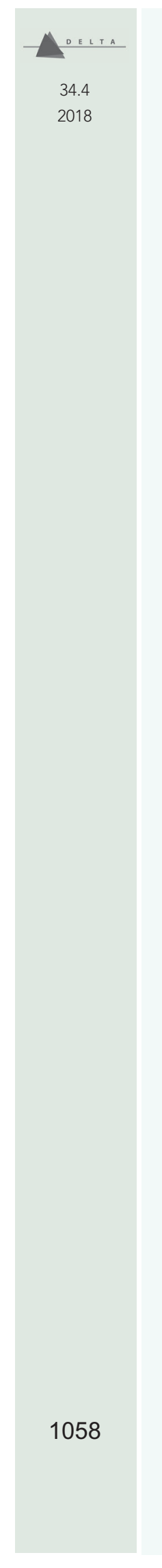

Beatriz Furtado Alencar Lima, Izabel Magalhães

\begin{tabular}{|l|l|l|}
\hline (1) A gente & vive & em desvantagem em relação às outras pessoas \\
\hline Ator & Processo material & $\begin{array}{l}\text { Elemento circunstancial de modo (subtipo } \\
\text { comparação) }\end{array}$ \\
\hline
\end{tabular}

Ao utilizar o processo material "vive" para referir-se às circunstâncias em que se encontram as pessoas cegas, Leda apresenta-nos, sem modalizações, a realidade de exclusão e discriminação em que suas práticas de letramento (ver seção 2) encontram-se situadas. Não se trata de uma situação momentânea e passageira referente ao acesso à leitura e à escrita, mas de uma vivência das pessoas cegas. Vivência cujos modos circunstanciais indicam a comparação ("relação de desvantagem") em relação a um grupo de pessoas que detêm a possibilidade de experienciar suas práticas de letramento através de uma atividade corporal, a da visão, ainda hegemônica em nossa sociedade.

A comparação que se estabelece por meio da circunstância de modo (subtipo comparação) marca, linguisticamente, a qualidade circunstancial "em desvantagem" de vida das pessoas cegas, alegando, categoricamente, a assimétrica e injusta situação que se estabelece entre dois grupos de pessoas em razão dos diferenciais que apresentam para entrar em contato com a informação nas práticas de letramento em que se situam.

Se analisarmos a oração de Leda desde a perspectiva da Metafunção Textual, cuja função está associada ao sistema da informação Tema/ Rema, podemos dizer que, ao apresentar o grupo nominal "a gente" como Tema da sentença, Leda prioriza-o em sua mensagem e, dessa maneira, dá destaque à desvantagem dos sujeitos cegos em relação às outras pessoas, e não à vantagem desses indivíduos em relação às pessoas cegas.

\begin{tabular}{|l|l|}
\hline (1) A gente & vive em desvantagem em relação às outras pessoas \\
\hline Tema (grupo nominal) & Rema \\
\hline
\end{tabular}

O ponto principal da mensagem, o elemento que localiza e orienta a oração dentro do contexto, são as pessoas cegas; elas é que são o destaque, o ponto nuclear a partir do qual se diz algo. No contexto assimétrico em que se encontram as pessoas cegas, Leda busca a 
revisão/inversão dessa assimetria por meio tanto do conteúdo de sua declaração reivindicativa como por meio da maneira como ela estrutura o funcionamento dos elementos de sua reivindicação. Maneira essa que aqui implica a localização dos termos na oração ("a gente", e não "as outras pessoas" como Tema), bem como a escolha de determinado vocabulário em detrimento de outro. Sobre essa escolha, observemos o uso do item lexical "desvantagem", que se refere às pessoas cegas, em vez de "vantagens", que se referiria às outras pessoas.

Além disso, atentamos também para o fato de que Leda, de alguma forma, percebe a instabilidade da ordem hegemônica em que se encontra, levando em consideração o processo material e relacional atributivo que elege para a construção das orações:

\begin{tabular}{|c|c|c|c|}
\hline (1) A gente & vive & \multicolumn{2}{|c|}{ em desvantagem em relação às outras pessoas } \\
\hline Existente & Processo material & \multicolumn{2}{|c|}{ Circunstância de modo (subtipo qualidade) } \\
\hline (2) Nós & estamos & & acostumadas \\
\hline Portador & Processo relacion & tributivo & Atributo qualificativo \\
\hline
\end{tabular}

A utilização dos verbos "vive", em (1) "a gente vive em desvantagem", e "estamos", em (2) "pessoas cegas que estamos acostumadas a conviver", nessas orações de função declarativa, traduz, respectivamente: em primeiro lugar, a regularidade/estabilidade de uma situação de desigualdade e de injustiça que faz parte, circunstancialmente, dos eventos sociais de que participam as pessoas cegas; observemos que Leda opta pela utilização do processo material "vive" para narrar a comparação das circunstâncias em que vivem ela e as demais pessoas como seres humanos cegos. Em segundo lugar, que o acostumar-se a essa desigualdade não se trata de uma situação que constitua as ações das pessoas cegas, uma vez que Leda declara que "estão" acostumados, e não que "são" acostumados. O costume é um atributo que se relaciona às pessoas cegas, mas não de maneira permanente, dada a utilização do processo relacional "estamos". A atribuição relacionada aos portadores ("nós") não se constitui como uma identidade das pessoas cegas.

Atentemos igualmente para o fato de que, na primeira declaração, a regularidade/estabilidade é apresentada não em um tom que atesta 


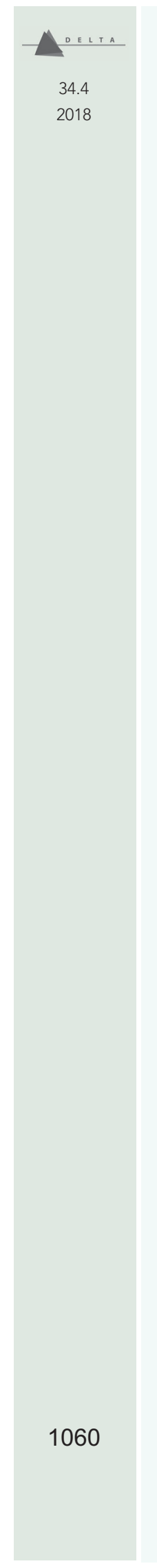

Beatriz Furtado Alencar Lima, Izabel Magalhães

a situação como isenta a mudanças, e sim em uma perspectiva de denúncia sobre uma situação que se apresenta como estável.

Seguindo as análises sobre o primeiro excerto, observamos que Leda constrói um discurso e constrói-se por intermédio dele como uma pessoa que, ainda que seja afetada pela falta de acessibilidade e pelo descaso da sociedade, posiciona-se de maneira ativa e não resignada diante do contexto em que se encontra. Justificamos essa nossa observação por meio das seguintes declarações de Leda: "as adaptações quem faz sou eu"; "como eu tenho necessidade, eu encontro o meu meio", as quais apontam para a sua não aquiescência diante dos eventos de letramento de que participa.

Halliday e Matthiessen (2004:175, tradução nossa) elencam três componentes os quais se organizam em modelos ou esquemas que permitem a construção representacional de nossas experiências no mundo, quais sejam: "1. Um processo de desdobramento através do tempo; 2. Os participantes envolvidos no processo; 3 . As circunstâncias associadas ao processo". Levando em consideração esses elementos para refletir sobre as declarações de Leda supracitadas, podemos dizer que: é Leda a responsável (quem faz?) pelas adaptações (o quê?) para ela mesma (para quem?) dentro das circunstâncias adversas e inacessíveis em que vive: "elas não vieram adaptadas para eu usar, elas não vieram para mim" (sob que circunstâncias?); é Leda quem (quem faz?) tem a necessidade (o quê?) e é ela quem encontra (quem faz?) o meio (o quê?) para satisfazer a própria necessidade (para quem?), com o intuito de "pelo menos conviver como todo mundo". No Sistema de Transitividade, temos a seguinte organização das funções dessas orações no sistema:

\begin{tabular}{|l|l|l|l|l|}
\hline $\begin{array}{l}\text { (3) As } \\
\text { adaptações }\end{array}$ & quem & faz & sou & eu \\
\hline Meta & Ator e meta & $\begin{array}{l}\text { Processo } \\
\text { material }\end{array}$ & $\begin{array}{l}\text { Processo relacional } \\
\text { identificativo }\end{array}$ & Identificado/Valor \\
\hline
\end{tabular}

Nessa oração (3), o processo material (faz) descreve a ação de Leda, apontando para a sua iniciativa diante do fato de as adaptações não serem projetadas para ela. Essa iniciativa de Leda realça-se com a identificação relacional que ela constrói com as próprias adaptações 
que precisa fazer. Uma vez que podemos subentender a segunda oração da seguinte maneira:

\begin{tabular}{|l|l|l|}
\hline (3) $\mathrm{Eu}$ & sou & as adaptações \\
\hline Identificado/Valor & Processo relacional identificativo & Identificador/Símbolo \\
\hline
\end{tabular}

Afirmamos que Leda valoriza-se por meio de uma identificação com as adaptações: fazer as adaptações é a identidade de Leda. Em seu agir para alcançá-las, com elas se identifica. As adaptações constituemse, em sua fala, tanto como meta a ser alcançada quanto como característica que a valoriza na condição de uma pessoa que age/intervém em um mundo não adaptado para ela. Além disso, Leda também se representa tanto como o Ator quanto como a Meta, haja vista que ela é igualmente a Meta para onde se dirigem suas ações.

A iniciativa a que nos referimos aparece novamente por meio das orações que se seguem (4 e 5), nas quais Leda se autorrepresenta como a portadora das necessidades e como o ator que realiza (e não o que sofre) a ação de atingir sua meta. Diante da circunstância ("para eu poder ter acesso, ou pelo menos conviver como todo mundo"), mais uma vez Leda: (1) coloca-se como o elemento que vem primeiro na sentença (Tema), priorizando-se em sua mensagem e, portanto, chamando a atenção para a sua necessidade; (2) assume o primeiro plano de quem toma para si a iniciativa de um processo material.

\begin{tabular}{|l|l|l|l|l|l|l|}
\hline (4) Como & $e u$ & tenho & necessidade & (5) eu & encontro & $\begin{array}{l}\text { o meu } \\
\text { meio }\end{array}$ \\
\hline $\begin{array}{l}\text { Circunstância } \\
\text { de causa (sub- } \\
\text { tipo razão) }\end{array}$ & Portador & $\begin{array}{l}\text { Processo } \\
\text { relacional } \\
\text { atributivo }\end{array}$ & Atributo & Ator & $\begin{array}{l}\text { Processo } \\
\text { material }\end{array}$ & Meta \\
\hline
\end{tabular}

Atrelado ao Sistema de Transitividade e à função textual associada ao sistema de informação (Tema/Rema), podemos também afirmar que a iniciativa reivindicativa de Leda encontra-se presente nas orações mediante a utilização explícita (escolha do léxico) do pronome pessoal "eu", bem como dos possessivos "minha" e "meu". Nesse primeiro excerto, a tentativa de ajustamento de Leda dá-se não como uma conformação à Ordem Visiocêntrica do Discurso, mas como uma 
necessidade de inserir-se minimamente nas circunstâncias em que convive (quase) "todo mundo". O ajustamento conformativo a essas circunstâncias concretiza-se antes como uma construção particular de empoderamento diante de uma ordem que a desempodera do que como um ajustamento para mantê-la.

Se apresentamos o desabafo de Leda sobre a dificuldade no acesso à tecnologia no primeiro excerto, na passagem adiante, a retórica segue com reivindicação sobre as dificuldades em ler o que deseja:

Excerto (2): Leda: Eu leio um pouco de tudo. Ou, então, leio o que me dão. Não leio o que eu posso, eu leio o que me dão, né? Eu leria o que eu posso se eu pegasse um livro hoje na livraria e eu lesse o que eu quisesse, né? Então, às vezes, eu leio o que o povo quer; às vezes, eu leio o que eu quero, mas nem tudo o que eu posso e que eu gostaria. [...] Essa história desse povo aí doutorado, não sei o quê, não sei o quê [...] quando os livros estão mofados é que os cegos vão ter acesso. Então, por isso que eu digo que eu não leio o que eu quero, eu leio o que as pessoas querem que eu leia ou que está disponibilizado na internet, né? E o que eu preciso ler dentro da minha área, dentro do que eu gostaria de fazer, não está disponibilizado na internet, e as pessoas não fazem essas coisas para as pessoas cegas...

Bia: $\mathrm{Na}$ área científica, né?

Leda: [...] Área científica, exatamente. As pessoas cegas são as últimas a ler. Quando a gente vai ler, ninguém nem lê mais. (Leda) ${ }^{17}$.

Percebamos que Leda não fala sobre o que ela lê. Em vez de falar sobre o que lê, ela faz uma reivindicação quanto ao que gostaria de ler, mas não lhe é possível devido à falta de materiais disponíveis para pessoas cegas. Ela assume uma posição reivindicativa contra uma sociedade que estabelece os seus parâmetros de distribuição e consumo de leitura baseada em critérios que se centram num acesso única e exclusivamente visual. Leda deixa clara e explícita sua reivindicação contra as práticas de letramento em que se encontra situada, as quais se baseiam numa Ordem Visiocêntrica do Discurso.

Quando Leda traz à tona a questão da falta de disponibilidade de materiais múltiplos e acessíveis para as diferentes práticas de letramento das pessoas cegas, é importante atentarmos para alguns marcos legais, 
tais como: a Lei do Livro Acessível ${ }^{18}$, o Decreto n. 5.296/2004 ${ }^{19}$, a Campanha do Livro Acessível no Brasil (movimento organizado por um cego $)^{20}$ e a Convenção da Organização das Nações Unidas (ONU) sobre os Direitos das Pessoas com Deficiência, cujas partes signatárias da convenção, inclusive o Brasil, são obrigadas a garantir o pleno gozo dos direitos humanos às pessoas com deficiência, entre eles, o direito à informação. Sobre essa convenção, Palacios (2008:235-236, tradução nossa) apresenta-a como um instrumento:

[...] resultado de um longo processo, no qual participaram vários atores, entre os quais se destacam os estados-membros das Nações Unidas, observadores das Nações Unidas, corpos e organizações importantes das Nações Unidas, relator especial sobre deficiência, instituições de direitos humanos nacionais e organizações não governamentais, dentre as quais tiveram um papel destacado as organizações de pessoas com deficiência. Esse novo instrumento supõe importantes consequências para as pessoas com deficiência, contando como as principais: a 'visualização' dessa coletividade dentro do sistema de proteção dos direitos humanos das Nações Unidas, a assunção inquestionável do fenômeno da deficiência como uma questão de direitos humanos e o contar com uma ferramenta jurídica vinculante à hora de fazer os direitos dessas pessoas.

São legislações que buscam assegurar o acesso pleno e irrestrito às maneiras pelas quais as pessoas cegas interagem com a leitura e com a escrita. Trata-se de marcos legais que convergem com o que diz José

18. Trata-se de uma Lei Federal de número 10.753, promulgada em 31 de outubro de 2003. Ficou conhecida como Lei do Livro Acessível porque seu objetivo maior foi instituir a política nacional do livro e da leitura no Brasil, tendo como uma das principais diretrizes, consoante o inciso I de seu artigo $1^{\circ}$ : "Assegurar ao cidadão o pleno exercício do direito de acesso e uso do livro".

19. É o decreto que regulamenta a Lei n. 10.753/2003.

20. Informações várias e detalhadas sobre essa campanha encontram-se no sítio eletrônico Livro Acessivel Universal, que faz a divulgação do Movimento pelo Livro e pela Universidade Acessíveis. A página eletrônica tem como idealizador Naziberto Lopes de Oliveira, coordenador do Movimento pelo Livro e Leitura Acessíveis no Brasil (Molla). A partir do Molla, surge o Grupo de Trabalho (GT) do Livro Acessível, posteriormente chamado de GT de Acessibilidade. O grupo reunia-se periodicamente na Fundação Biblioteca Nacional do Rio de Janeiro, mais especificamente no âmbito da Câmara Setorial do Livro e da Leitura (CSLL). O objetivo do GT era a regulamentação da Lei n. 10.753/2003. Por meio desse grupo, o Molla, com menos de um ano de existência, saiu do anonimato para marcar sua presença dentro do grupo de acessibilidade do Ministério da Cultura, criado para elaborar o texto do decreto de regulamentação da lei anteriormente citada. 


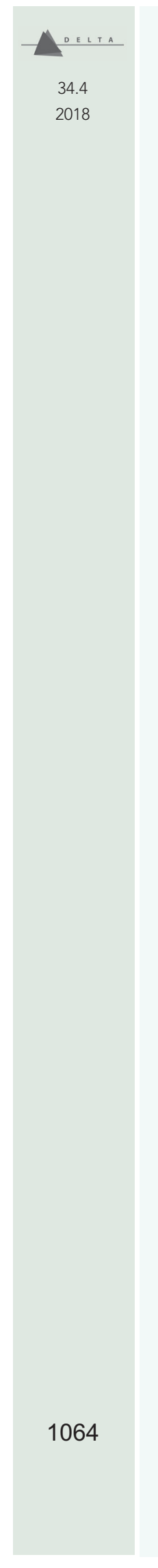

Beatriz Furtado Alencar Lima, Izabel Magalhães

Diquissone Tole (representante da União Africana de Cegos) sobre os desafios que se colocam para o futuro na forma como as pessoas com deficiência visual se organizam para autorrepresentar seus direitos e interesses:

Muitos desafios. Em primeiro lugar é preciso melhorar o acesso e sucesso escolar das PCDVs [pessoas com deficiências visuais]. Como sabe, para exercer eficazmente a autorrepresentação, é preciso desenvolver habilidades, ter consciência dos seus direitos como cidadão, ter capacidade de análise dos fatores de constrangimento, e isso só se consegue com uma educação crítica e de qualidade. Associado a isso está toda a problemática de acesso a equipamentos Braille, novas tecnologias, informação em formato apropriado, sensibilização das famílias, professores ativistas e qualificados [...]. (Reyman 2012:10).

A justaposição entre o conteúdo desses marcos e o conteúdo com o qual nos deparamos nos dois excertos de Leda leva-nos à seguinte constatação: "As transformações legislativas relativas à deficiência não têm sido acompanhadas por uma dinâmica de transformação das percepções sociais acerca da deficiência” (Martins 2012:3). Ou seja, encontramos aí um grande descompasso entre o que se observa nas legislações e o que as pessoas cegas vivenciam ao se depararem com as barreiras arquitetônicas, atitudinais, informacionais, linguísticas, entre outras, as quais permanecem reforçando uma suposta deficiência em pessoas que experienciam práticas de contato com a informação, presente nas paisagens linguísticas (Coulmas 2014) contemporâneas, fora dos padrões de uma hegemonia visiocêntrica. Utilizamos o termo "paisagem linguística" a partir da reflexão de Coulmas sobre as implicações da presença da escrita no ambiente urbano como um fator desencadeador de duas questões imbricadas uma na outra: o aparecimento de uma nova configuração que implica o visual para a comunicação entre as pessoas e, com isso, o despontar do âmbito da esfera pública:

A escrita na praça do mercado é quintessencialmente pública. Ela modifica o ambiente físico, acrescentando-lhe uma dimensão visual de comunicação que traz em seu rastro novas formas de interação e consciência. Assim emerge uma paisagem linguística - mais apropriadamente, talvez, uma paisagem linguística urbana - em que a língua não é apenas ouvida, mas também vista, o que permite ao espectador contemplar e rever as mensagens que outros lhe 
legaram há um momento ou há uma década atrás, conforme o caso. Com a história do objeto inscrito e da inscrição, também a história linguística se torna parte do cenário. (Coulmas 2014:41).

Observemos que essa modificação baseia-se em "uma dimensão visual de comunicação". Não queremos aqui recriminar ou negar o visual, mas atentar criticamente para a questão da presença de uma arqueologia dominante de práticas centradas na visão, construídas desde os primórdios da relação do ser humano com a comunicação escrita. Diante desse cenário, reiteramos o questionamento sobre onde, de fato, encontra-se o que se convencionou denominar de deficiência visual. Responder à questão em termos dicotômicos, como, por exemplo, apontando ou para a arqueologia dominante de práticas centradas na visão ou para as pessoas com deficiência visual, pode conduzir a reducionismos estanques sobre uma situação social que exige reflexões transdisciplinares mais amplas. O que percebemos, no entanto, é que, ao localizar e engessar a resposta no segundo polo para o qual apontamos, retiramos e eximimos, dessa forma, a deficiência, que, na verdade, localiza-se (em grande parte) na sociedade, e não nas diversidades funcionais dos seres humanos.

Seguindo o percurso a que nos propomos neste artigo, damos continuidade às análises com o excerto (3) que se segue:

Excerto (3): [...] (6) eu acho que os déficits que eu tive, ou (7) que eu venho tendo até então, (8) são por causa da minha cegueira, mas não em decorrência da minha leitura e da minha escrita, né, do código, do sistema que eu escolhi para fazer parte da minha leitura e da escrita. Então, o Braille, para mim, ele me completa, eu não tenho nenhuma dificuldade nem para ler nem para escrever. (Leda) ${ }^{21}$.

Se, nos dois primeiros excertos, a tônica residiu em uma posição reivindicativa de Leda em relação ao que denominamos de uma Ordem Visiocêntrica do Discurso, aqui observamos que a tônica recai nos déficits que a participante atribui à sua cegueira. Ou seja, percebemos, nesse fragmento da fala de Leda, uma oscilação - se comparado aos dois fragmentos primeiramente apresentados - que pende para um 


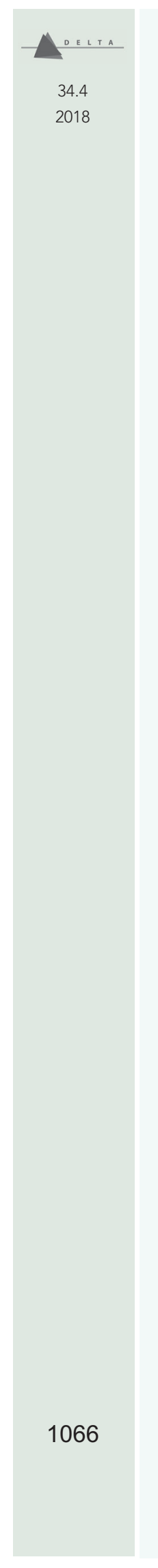

Beatriz Furtado Alencar Lima, Izabel Magalhães

ajustamento conformativo, tomando como referência a Ordem Visiocêntrica do Discurso. Por meio da funcionalidade de seus elementos constitutivos, a análise das orações 6,7 e 8, ajuda-nos a compreender esse ajustamento a que nos referimos:

\begin{tabular}{|l|l|l|l|l|l|}
\hline (6) $E u$ & acho & que os déficits & que & eu & tive \\
\hline Experienciador & $\begin{array}{l}\text { Processo } \\
\text { mental } \\
\text { (cognição) }\end{array}$ & Fenômeno & Atributo & Portador & $\begin{array}{l}\text { Processo } \\
\text { relacional } \\
\text { atributivo }\end{array}$ \\
\hline
\end{tabular}

\begin{tabular}{|l|l|l|l|}
\hline (7) que & $e u$ & venho tendo & até então \\
\hline Atributo & Portador & $\begin{array}{l}\text { Processo relacional atri- } \\
\text { butivo }\end{array}$ & $\begin{array}{l}\text { Circunstância de localização } \\
\text { (subtipo tempo) }\end{array}$ \\
\hline
\end{tabular}

\begin{tabular}{|l|l|l|}
\hline $\begin{array}{l}\text { (8) os déficits (característica } \\
\text { subentendido) }\end{array}$ & são & por causa da minha cegueira \\
\hline Característica & $\begin{array}{l}\text { Processo relacional } \\
\text { identificativo }\end{array}$ & Valor \\
\hline
\end{tabular}

Observemos que Leda atribui os déficits que teve ou vem tendo em sua cegueira à sua falta de visão física, e não à sociedade, a qual, em sua deficiência para lidar com as diversidades funcionais humanas, ocasiona diversos déficits a pessoas cegas, surdas, paralíticas, entre outras. Referindo-nos especificamente às pessoas cegas, esses déficits centram-se, por exemplo, de maneira bastante acentuada, em uma paisagem linguística centrada na visão e inacessível, por conseguinte, a homens e mulheres que vivenciam suas práticas de letramento mediante outros sentidos (tato, audição, olfato) que fogem ao paradigma desse cenário. Pensemos nos livros elaborados para a alfabetização de crianças com deficiência visual. Neles encontramos, ilustrações por meio do tato como por meio do olfato. Por exemplo, para falar de flores, ou para o trabalho com as cores associando-as a sabores e cheiros.

Leda processa a relação - que atribui a ela os déficits (que vem tendo até então) - na forma de uma função declarativa. Nesta, os déficits apresentam-se como um fato em sua vida até o presente momento. Ao declarar esse fato, não percebemos um questionamento sobre a exis- 
tência e permanência deles; também não encontramos uma referência - externa a ela - sobre quem seria(m) o(s) responsável(is) por esses déficits. O que a participante afirma é que eles não se relacionam à sua leitura ou à sua escrita, tampouco ao código que escolheu para realizálas. Ainda que modalize o processo mental cognitivo com a escolha do processo "acho" (oração 6), encontramos mais adiante (oração 7) uma categorização na qual o valor da cegueira caracteriza-se como um déficit. Ou seja, os déficits podem não se relacionar à sua leitura e escrita, mas o valor da cegueira caracteriza-se como um déficit para Leda.

Observamos ainda que a característica de déficit aparece como o tema na oração 8 - ainda que se trate de uma característica subentendida na oração -, o que enfatiza a característica déficit. A cegueira de Leda está em segundo plano (Rema) ante os déficits que a caracterizam. Em contraste com a posição reivindicativa que pudemos observar nos dois primeiros excertos, percebemos aqui uma mudança na qual a deficiência volta a localizar-se na diversidade funcional dos seres humanos, e não na sociedade. Constatamos, pois, conforme sinalizamos ao início das análises, a oscilação entre uma reivindicação aos contextos engendrados pela Ordem Visiocêntrica do Discurso e um ajustamento conformativo a ela.

\section{Conclusão}

Em nossas reflexões, investigamos as representações de Leda sobre alguns dos contextos de letramento em que ela está situada. Na perspectiva do estudo sobre o sistema gramatical como um significado representacional, examinamos a oração como uma estrutura utilizada "[...] para representar as experiências dos indivíduos, como estes veem o mundo" (Andrade \& Taveira 2009:54). Dos excertos que analisamos, verificamos que Leda representa seu contexto de leitura e de escrita com as seguintes posições: uma realidade que se apresenta em desvantagem em relação à realidade das demais pessoas e, nesse contexto, portanto, é ela quem precisa fazer as adaptações necessárias para conseguir a acessibilidade de informações; uma realidade de grande dificuldade para conseguir encontrar o que necessita ler, tendo em vista, mais uma vez, a inacessibilidade; uma realidade de déficits por conta de sua cegueira. 
Conforme observamos, as posições de Leda oscilaram entre uma reivindicação explícita e notória aos contextos engendrados pela $\mathrm{Or}$ dem Visiocêntrica do Discurso e um ajustamento conformativo ${ }^{22}$ a ela. Ao apresentarmos essa configuração, nosso intuito reside em mostrar que a potencialidade do poder reivindicativo dessa participante - que aqui representa o clamor uníssono dos/as demais cegos/as que fizeram parte de nossa pesquisa de doutoramento - pode vir a concretizar-se por intermédio da percepção desses ajustamentos conformativos que ajudam na manutenção e na perpetuação de uma ordem promotora de sérias desigualdades, injustiças e assimetrias entre os seres humanos em suas diversidades funcionais.

Acreditamos que, ao tornarmos explícito o movimento das posições de Leda sobre a Ordem Visiocêntrica do Discurso, tanto em suas intervenções desafiadoras ao status quo quanto em seu ajustamento conformativo a ele, é possível seguir, de maneira consistente e desafiadora, a desestabilização de uma ordem social excludente, levando em conta que "[...] a reprodução da ordem social não exige um consenso subjacente profundo a respeito de valores e crenças, desde que haja um dissenso suficiente para prevenir a formação de um movimento efetivo de oposição" (Thompson 2011:122).

$\mathrm{Na}$ entrevista de Leda, um segundo aspecto que entendemos como uma "forma incipiente da crítica da ideologia" consiste nos subsídios que encontramos em seu texto para afirmar que a deficiência não se encontra em sua maneira particular de experienciar o mundo, mas em uma visão restrita e deficiente da sociedade, que permanece sem querer enxergar as diferentes vivências e necessidades de acesso à informação que condizem à realidade das pessoas cegas. Ao falarmos em uma "forma incipiente da crítica da ideologia", referimo-nos diretamente ao conceito de Thompson sobre as intervenções desafiadoras e transformadoras de formas ideológicas (no caso de nosso trabalho, a Ordem Visiocêntrica do Discurso constitui-se como uma forma ideológica) que: “[...] frequentemente, são, de fato desafiadas, tanto explicitamente, em ataques articulados e organizados, como implicitamente, nas trocas simbólicas corriqueiras do dia a dia" (Thompson 2011:91).

22. Entendemos por ajustamento conformativo as posições que a participante apresenta ao buscar, em alguma medida, o amoldamento a uma ordem que explícita e/ou implicitamente dita valores hegemônicos sobre os meios, modos e atividades corporais a serem utilizados na interação do ser humano com o meio ambiente em suas práticas sociais. 
Almejamos, neste artigo, igualmente proporcionar uma reflexão sobre o vocábulo "deficiente", o qual entendemos como mantenedor de uma perspectiva hegemônica e excludente a respeito das pessoas cegas, surdas, paralíticas, entre outras diversidades funcionais humanas ${ }^{23}$. Entendemos que o termo atribui características e engendra responsabilidades a um determinado grupo de pessoas, sendo tais características e responsabilidades, na maioria das vezes, pertencentes a uma sociedade ainda repleta de barreiras excludentes e discriminatórias. Acreditamos que a mudança de enfoque sobre quem vem a ser o deficiente e o que podemos entender como deficiência poderá também contribuir para o fortalecimento das reivindicações das pessoas cegas.

Recebido em: 17/02/2016

Aprovado em: 07/05/2018

E-mails: alencarbia@gmail.com mizabel@uol.com.br

\section{Referências bibliográficas}

Andrade, Clebson Luiz \& Taveira, Valdirécia de Rezende. 2009. Introdução à Gramática Sistêmico-Funcional. In: LiMA, Cássia Helena Pereira; Pimenta, Sonia Maria de Oliveira \& Azevedo, Adriana Maria Tenuta de (org.). Incursões semióticas: teoria e prática de gramática sistêmico-funcional, multimodalidade, semiótica social e análise crítica do discurso. Rio de Janeiro: Livre Expressão. p. 48-55.

BoLt, David. 2005a. From blindness to visual impairment: terminological typology and the social model of disability. Disability \& Society, (20) 5: 539-552.

2005b. Looking back at literature: a critical reading of the unseen stare in depictions of people with impaired vision. Disability \& Society, (20) 7: 735-747.

2006. Beneficial blindness: literary representation and the socalled positive stereotyping with impaired vision. New Zeeland Journal of Disability Studies, 12: 80-100.

Coulmas, Florian. 2014. Escrita e sociedade. São Paulo: Parábola.

Dinız, Debora. 2012. O que é deficiência. São Paulo: Brasiliense.

23. Para uma discussão mais aprofundada sobre os problemas terminológicos concernentes à cegueira, sugerimos a leitura de Bolt (2003, 2005a, 2005b). 
Fairclough, Norman. 2003. Analysing discourse: textual analysis for social research. London/New York: Routledge.

2012. A dialética do discurso. In: Magalhães, Izabel (org.). Discursos e práticas de letramento: pesquisa etnográfica e formação de professores. Campinas: Mercado de Letras. p. 93-107.

Halliday, Michael \& Matthiessen, Christian Matthias Ingemar Martin. 2004. An introduction to functional grammar. London: Arnold.

Martins, Bruno Sena. 2006. E se eu fosse cego? Narrativas silenciadas da deficiência. Porto: Afrontamento.

.2012. A cegueira em Portugal: representações e silenciamentos. Louis Braille: Revista especializada para a área da deficiência visual, Lisboa, 4: 3-4.

Palacios, Agustina. 2008. El modelo social de discapacidad: orígenes, caracterización y plasmación en la convención internacional sobre los derechos de las personas con discapacidad. Madrid: Cinca.

Ramalho, Viviane \& Resende, Viviane de Melo. 2009. Análise de discurso crítica. São Paulo: Contexto.

.2011. Análise de discurso (para a) crítica: o texto como material de pesquisa. Campinas: Pontes.

Resende, Viviane de Melo. 2009. Análise de discurso crítica e realismo crítico: implicações interdisciplinares. Campinas: Pontes.

Reyman, Renate. 2012. Nada sobre nós sem nós. Louis Braille: Revista especializada para a área da deficiência visual, Lisboa, 4: 5-10.

Rıos, Guilherme. 2009. Literacy discourses. A sociocultural critique in Brazilian communities. Saarbrücken: Verlag Dr. Müller.

SiLVA, Luzia Rodrigues da. 2008. As identidades femininas: discurso e letramento no contexto escolar. 2008. $337 \mathrm{f}$. Tese (Doutorado em Linguística) - Departamento de Linguística, Português e Línguas Clássicas, Universidade de Brasília, Brasília.

2013. Rosa, uma professora: a co-existência de diferentes discursos. In: SATO, Denise Tamaê \& JÚNIOR, José Ribamar Batista (org.). Contribuições da análise de discurso crítica no Brasil. Uma homenagem a Izabel Magalhães. Campinas: Pontes. p. 53-68.

Taveira, Valdirécia de Rezende. 2009. Gramática Sistêmico-Funcional: a Metafunção Ideacional. In: LimA, Cássia Helena Pereira; Pimenta, Sonia Maria de Oliveira \& Azevedo, Adriana Maria Tenuta de (org.). Incursões semióticas: teoria e prática de gramática sistêmicofuncional, Multimodalidade, semiótica social e análise crítica do discurso. Rio de Janeiro: Livre Expressão. p. 74-86.

Thompson, John Brookshire. 2011. Ideologia e cultura moderna: teoria social crítica na era dos meios de comunicação de massa. Petrópolis: Vozes. 